\title{
Determination of Flavonoid Contents and Evaluation of in vitro Antioxidant Activities of the Extract of Selected Citrus Fruit Peel
}

\author{
Olyad Erba $(D)$ 1, , Dereje Atomsa $(D)$, Meseret Chimdessa ${ }^{(D)}$, Teshome Gonfa ${ }^{(D 2}$ \\ ${ }^{1}$ School of Biological Sciences and Biotechnology, College of Natural and Computational Sciences, Haramaya \\ University, Ethiopia \\ ${ }^{2}$ Department of Chemistry, College of Natural and Computational Sciences, Haramaya University, Ethiopia
}

\begin{abstract}
Flavonoids capture and neutralize the oxidative agents, and quench free radicals. The peel which represents almost one half of the fruit mass has been found to be the main sources of total phenols and flavonoids in the citrus fruit. In present study, flavonoid content and in vitro antioxidant activities of ethanol extracts from some selected citrus fruit peels grown in Ethiopia were determined. Colorimetric aluminum chloride was used for flavonoid content determination. In vitro antioxidant properties of the citrus fruit peels were determined by measuring DPPH and Nitric Oxide radical scavenging activity, and reducing power. The study result showed that lemon peel contained significantly the highest flavonoid content $(8.88 \pm 0.621 \mathrm{mg}$ of quercetin equivalent/g of extract) at $100 \mu \mathrm{g} / \mathrm{ml}$ concentration. When compared to vitamin $\mathrm{C}$ used as standard, lemon peel extract showed significantly higher DPPH radical scavenging of $75.60 \pm 2.4 \%$. Lime peel extract showed highest $(0.38$ \pm 0.01 ) reducing power activity at $1000 \mu \mathrm{g} / \mathrm{mL}$ concentrations. Strong linear correlations was observed between flavonoid contents of selected citrus peel extract and DPPH free radical scavenging activity $(\mathrm{r}=0.975, p=0.025)$. Overall, in vitro antioxidant potential of citrus fruit peels extract grown in Ethiopia was confirmed and correlation between in vitro antioxidant activity and flavonoid content of citrus peel extract showed different trends. Further analysis is required to purify specific structure of flavonoid components of citrus fruit peel from Ethiopian cultivar using advanced purification techniques.
\end{abstract}

\section{ARTICLE HISTORY}

Received: December 28, 2019

Revised: February 01, 2020

Accepted: February 27, 2020

\section{KEYWORDS}

Antioxidant activity, Total flavonoid,

Correlation,

Lemon peel

\section{INTRODUCTION}

The most important free radical in biological systems is reactive oxygen species (ROS) and reactive nitrogen species (RNS). These reactive species are harmful by-products generated during the normal cellular functions [1]. Harmful effects of free radicals in the living system could presumably be prevented by naturally occurring antioxidants [1,2]. A search for effective, nontoxic natural compounds with antioxidant activity has been intensified in recent year [3]. Fruits of citrus genus are recognized as being a healthful source of bioactive compounds such total polyphenols, dietary fibre, essential phenolics and ascorbic acid [4]. Flavonoids are widely distributed group of bioactive compounds [5]. Flavonoids act on

CONTACT: Olyad ERBA $₫$ olyaderba@gmail.com $\equiv$ School of Biological Sciences and Biotechnology, College of Natural and Computational Sciences, Haramaya University, Ethiopia 
biological systems as anti-oxidants, anti-viral, anti-inflammatory and anti-tumoral agents. They capture and neutralize the oxidative agents, and quench free radicals [6].

The peel which represents almost one half of the fruit mass has been found to be the main sources of total phenols and flavonoids in the citrus fruit [7-10]. Pulp of wild mandarin has been tested and showed a good source of phytochemicals and natural antioxidants [11]. Peel residues from sweet and bitter oranges, lemons, and mandarins have proved to be an important source of phenolic acids and flavonoids, flavanones, and glycosylated flavanones [12].

In Ethiopia, citrus is one of the most economically important fruit crops grown by smallholders and commercial farmers. Sweet orange, mandarin, lime, lemon, grapefruit, citrus hybrids, sour orange and citron are among commonly cultivated citrus fruits [13].

Many scientific articles stated that phytochemical content and composition varies due to different factors and one of the factors indicated is environmental difference and variety of the plant. As far as authors knowledge, there has been little work done on the flavonoid content and antioxidant activity of citrus fruit peel extracts grown in Ethiopia. Therefore, this was aimed to determine flavonoid contents and antioxidant activity of extract from orange, mandarin, lime and lemon peels collected from Dire Dawa District of Ethiopia.

\section{MATERIAL and METHODS}

\subsection{Plant Material Preparation and Extraction of Crude Extract}

Plant material preparation and extraction of crude flavonoid was carried out methods described by Cai et al. [14]. Fruits of sweet orange (Citrus sinensis), mandarin (Citrus reticulata), lime (Citrus aurantifolia) and lemon (Citrus limon) were collected at the ripening stage from Dire Dawa District farmers. The fruits were carefully hand peeled. The peels were cut into small pieces and dried in a ventilated oven at $60^{\circ} \mathrm{C}$ for one day. After drying, the peel fragments were ground for a few minutes in blinder and were refluxed with petroleum ether at $60^{\circ} \mathrm{C}$ for 8 hours to remove oil and chlorophyll. Then, the residue was air dried to evaporate petroleum ether. Crude flavonoid was extracted from the dried residue using soxhlet extractor with parameters of $80 \%$ ethanol, $78{ }^{\circ} \mathrm{C}$ and 5:1 (v/w) ratio for 6 hours. The filterate were concentrated over a rotary vacuum evaporator at $45^{\circ} \mathrm{C}$ until semi-solid extract was obtained. The resulting crude extract was freeze-dried and stored at $-20^{\circ} \mathrm{C}$.

\subsection{Screening and Determination of Flavonoid Contents}

Lead acetate method described by Sofowora [15] and ferric chloride method described by Ajayi et al. [16] was used to detect presence of flavonoids in the extracts. Colorimetric aluminum chloride method described by Ghasemi et al. [7] and Asjad et al. [8] was modified and used for flavonoid content determination. Concentration of $1 \mathrm{mg} / \mathrm{mL}$ of extract powder was prepared by dissolving in ethanol $(80 \%)$ and $1 \mathrm{~mL}$ of the extract solution was mixed with 0.1 $\mathrm{mL}$ of aluminium chloride $(10 \%), 0.1 \mathrm{~mL}$ of $1 \mathrm{M}$ potassium acetate, and $2.8 \mathrm{~mL}$ of distilled water. It was allowed to stay at room temperature for 30 minutes. The absorbance of the reaction mixture was measured at $415 \mathrm{~nm}$ with UV/Visible spectrophotometer. Distilled water was used as a blank. Flavonoid contents were calculated as quercetin equivalent from a calibration curve. Regression linear line of $Y=0.0067 x+0.0132 r^{2}=0.999$ of quercetin $(12.5-100 \mathrm{mg} / \mathrm{ml})$ was used as a reference standard curve $[7,8]$.

\subsection{Evaluation of Antioxidant Activity}

\subsubsection{DPPH·Scavenging Activity}

The stable 1, 1-diphenyl-2-picryl hydrazyl (DPPH) radical scavenging activity assay was carried out following methods described by Ghasemi et al. [7] and Asjad et al. [8]. Briefly, different concentrations of extracts and standard $(100 \mu \mathrm{g} / \mathrm{mL}, 200 \mu \mathrm{g} / \mathrm{mL}, 400 \mu \mathrm{g} / \mathrm{mL}, 800$ 
$\mu \mathrm{g} / \mathrm{mL}$ and $1000 \mu \mathrm{g} / \mathrm{mL}$ ) were prepared by using ethanol solvent. Each concentrations of extracts and standard $(4 \mathrm{~mL})$ and DPPH $(100 \mu \mathrm{M}$ in methanol, $4 \mathrm{~mL})$ was added in $10 \mathrm{~mL}$ capacity test tubes. The solution was mixed and allowed to stay for 15 minutes at room temperature in dark place. The absorbance was recorded at $517 \mathrm{~nm}$. Mixture of ethanol and methanol was used as a blank, DPPH solution without extract as a control and vitamin $\mathrm{C}$ as standard. The experiment was done in triplet. DPPH scavenging activity of extracts was calculated using the following equation:

$$
\text { Scavenging activity }(\%)=\frac{A_{517} \text { of control }-A_{517} \text { of sample }}{A_{517} \text { of control }} \times 100
$$

where, $\mathrm{A}_{517}$ of control is the absorbance of $\mathrm{DPPH} \cdot$ solution alone (without sample or standard solution addition) and $\mathrm{A}_{517}$ sample is the absorbance of mixture of DPPH solution and sample extract.

\subsubsection{Nitric Oxide Scavenging Activity}

Modified method of Munwar et al. [17] was used for nitric oxide scavenging activity assay. Different concentrations of extract $(100,200,400,800$ and $1000 \mu \mathrm{g} / \mathrm{mL})$ were prepared dissolving in ethanol. Sodium nitroprusside $(1 \mathrm{~mL}, 10 \mathrm{mM})$ in phosphate-buffered saline (PBS) was mixed with each of these concentrations $(2 \mathrm{~mL})$ separately and incubated at room temperature for 180 minutes. The same reaction mixture, without extract was served as control. After the incubation period, $3 \mathrm{~mL}$ of Griess reagent (1\% sulfanilamide, $2 \% \mathrm{H}_{3} \mathrm{PO}_{4}$ and $0.1 \%$ $\mathrm{N}$-(1- naphthyl) ethylenediamine dihydrochloride) was added. The absorbance of the chromophore formed was read at $546 \mathrm{~nm}$. Vitamin $\mathrm{C}$ was used as standard. The experiment was done in triplet. Nitric oxide radical (NO) scavenging activity of extracts was calculated using the following Equation:

$$
\text { Scavenging activity }(\%)=\frac{A_{546} \text { of control }-A_{546} \text { of sample }}{A_{546} \text { of control }} \times 100
$$

Where, $\mathrm{A}_{546}$ of control is the absorbance of sodium nitroprusside in PBS alone (without sample or standard solution addition) and $\mathrm{A}_{546}$ of sample is the absorbance of mixture of sodium nitroprusside in PBS and sample extract.

\subsubsection{Reducing Power Determination}

Reducing power of ethanol extracts of citrus fruit peel were determined using modified method of Al-anbari and Hassan [18] and Divya et al. [19]. The reducing power was measured at $100,200,400,800$ and $1000 \mu \mathrm{g} / \mathrm{mL}$ concentrations of ethanolic extract solution. Each concentration of ethanolic extract solution $(2 \mathrm{~mL})$ were mixed separately with phosphate buffer $(0.2 \mathrm{M}, \mathrm{pH} 6.6,2 \mathrm{~mL})$ and potassium ferricyanide $\left[\mathrm{K}_{3} \mathrm{Fe}(\mathrm{CN})_{6}\right](1 \%, 2 \mathrm{~mL})$ in to centrifuge tube $(10 \mathrm{~mL})$. The mixture was incubated at $35^{\circ} \mathrm{C}$ for $20 \mathrm{~min}$. Trichloroacetic acid $(2 \mathrm{~mL}, 10 \%)$ was added to the mixture to stop the reaction, which was then centrifuged at $3000 \mathrm{rpm}$ for 10 min. Two $\mathrm{mL}$ of upper layer of the solution was mixed with $2 \mathrm{~mL}$ of deionized water and $\mathrm{FeCl}_{3}$ $(0.25 \mathrm{~mL}, 0.1 \%)$. The absorbance was measured at $700 \mathrm{~nm}$. Increased absorbance of the reaction mixture indicated increased reducing power. Distilled water was used as a blank and Vitamin $\mathrm{C}$ as positive control.

\subsection{Statistical Analysis}

Experimental results were expressed as means \pm SD. All measurements were replicated three times. The data were analyzed by an analysis of variance $(p<0.05)$ and the means were separated by Duncan's multiple range tests. 


\section{RESULTS and DISCUSSION}

\subsection{Screening and Determination of Flavonoid Contents}

Preliminary screening of phytochemicals is a valuable step, in the detection of the bioactive principles present in medicinal plants and subsequently may lead to drug discovery and development [20]. In this study, the presence of total flavonoids in all citrus peel extracts was confirmed by lead acetate and ferric chloride test. In previous study, total flavonoid was screened and its presence in lemon and orange extracts was confirmed by similar methods [12].

The result of determination of total flavonoid content of the extracts was presented in Table 1. Flavonoid content was found in the range of $3.35 \pm 0.60$ to $8.88 \pm 0.62$ quercetin equivalent/g of extract powder. Lemon peel extracts contained significantly the highest total flavonoid content $(8.88 \pm 0.62 \mathrm{mg}$ quercetin equivalent/g of extract powder). Previous study on determination of total flavonoid contents of orange, lemon and mandarin ethanol peel extracts reported that the highest total flavonoid content was found in mandarin peel extract [12]. In this study, the total flavonoid content of mandarin and lime peels were $4.20 \pm 0.31 \mathrm{mg}$ quercetin equivalent/g of extract powder and $4.85 \pm 0.97 \mathrm{mg}$ quercetin equivalent/g of extract powder, respectively. Orange peel extract contained the lowest total flavonoid content $(3.35 \pm 0.60 \mathrm{mg}$ quercetin equivalent/g of extract powder). El Zawawy [12] reported higher content of total flavonoid in orange peel extract than total flavonoid content of orange peel extract in present study, but lower content of total flavonoid in lemon peel extracts compared to the result of content of total flavonoid in lemon extract found in present study. In other previous study, higher total flavonoid content for orange extract was reported [9]. Total flavonoid contents of lemon and orange peel extract that were nearly similar to the present study results were reported [21]. It was reported by many studies that variation in total flavonoid content were due to the use of different concentration of the solvent, methods of extraction, plant sample variety and mesh size of grinding. For example, particle size and solvent concentration [22], and citrus species and extraction solvents [23] were reported as factors that causes difference in flavonoid contents of extracts. In other studies, varieties of citrus species showed different contents of total flavonoid $[7,8]$ indicated variety as factor that causes variation in total flavonoid contents.

Table 1. Total flavonoid contents of citrus fruit peel extracts

\begin{tabular}{cc}
\hline Selected Citrus fruit & $\begin{array}{c}\text { Flavonoid contents } \\
\end{array}$ \\
\hline Orange & (in mg of quercetin equivalent/g of the extracts) \\
\hline Mandarin & $3.35 \pm 0.603^{\mathrm{A}}$ \\
Lime & $4.20 \pm 0.311^{\mathrm{A}}$ \\
Lemon & $4.85 \pm 0.971^{\mathrm{A}}$ \\
\hline
\end{tabular}

The values are Mean \pm Standard deviation $(n=3)$. Superscript letters compare means and similar letters show that the mean has no significant difference at $p<0.05$.

\subsection{In vitro Antioxidant Activity Determination}

Antioxidant activity should not be concluded based on a single antioxidant test model. In practice, several in vitro test procedures are carried out for evaluating antioxidant activities with the samples of interest [24]. It has been shown that some antioxidant assay methods give different antioxidant activity trends [17]. In this study, antioxidant activity of the fruit peels extracts was assessed by three different methods: DPPH radical scavenging, Nitric Oxide radical scavenging and reducing power determination. The results of antioxidant activity evaluation were presented in Figure 1, Figure 2 and Figure 3. 


\subsubsection{DPPH・Radical Scavenging}

In DPPH free radical scavenging activity assay, DPPH radical scavenging activity of the peel extracts ranged from $42.26 \pm 2.0$ to $75.60 \pm 2.0 \%$. The scavenging activity increased with the increasing concentrations of the peel extract from 100 to $400 \mu \mathrm{g} / \mathrm{mL}$. The extracts of orange, mandarin, lime and lemon showed the highest DPPH scavenging activity of $69.29 \pm 0.7 \%$ at $1000 \mu \mathrm{g} / \mathrm{mL}, 73.9 \pm 0.3 \%$ at $800 \mu \mathrm{g} / \mathrm{mL}, 67.14 \pm 5.9 \%$ at concentration of $400 \mu \mathrm{g} / \mathrm{mL}, 75.60 \pm$ $2.4 \%$ and $100 \mu \mathrm{g} / \mathrm{mL}$, respectively (Figure 1). Different researchers had reported percentage of DPPH radical scavenging which was within the range value of present scavenging assay result. Singh and Immanuel [21] reported the values of 71.4 and $75.9 \%$ for orange and lemon peel, respectively and El zawawy (2015) reported the value of $56.26 \pm 0.15$ for ethanolic mandarin peel extracts. Besides, El zawaway [12] reported DPPH radical scavenging of $41.400 \pm 10 \%$ and $50.66 \pm 0.25 \%$ for orange and lemon ethanolic extract, respectively. Arora and Kaura [25] reported $90 \%$ of DPPH radical scavenging for aqueous orange peel extract. The broader range of $14.18 \pm 1.85$ to $92.43 \pm 0.93 \%$ scavenging activity for DPPH radical was reported [10] and another a broader range of 1.336 to $97.714 \%$ DPPH scavenging activity of ethanol extract of satsuma mandarin peel was reported [26]. Orange peel extracts showed DPPH radical scavenging activity in a dose dependent manner. A similar trend reported in previous study [12]. DPPH radical scavenging of lime was found increase from 100 to $400 \mu \mathrm{g} / \mathrm{mL}$ concentration and then decrease a little bit. In agreement to this result, Lim and Loh [10] observed similar trends for kaffir lime and lime peel extract. During this study experiments, decolorization of violet color of DPPH solution was observed for all peel extracts. This showed that the selected citrus fruit peels exhibited a potential DPPH radical scavenging activity. The decoloration of DPPH solution is due to a hydrogen atom donation by extracts to DPPH [21, 24]. The molecules that involves in a reaction that causes decoloration is electron of nitrogen atom from DPPH radical and Hydrogen atom of hydroxyl group from antioxidant substances [22].

\subsubsection{Nitric Oxide Radical Scavenging}

In the nitric oxide free radical scavenging activity assay, Nitric Oxide scavenging activities of the peel extracts ranged from $62.96 \pm 2.2$ to $84.61 \pm 0.4 \%$. The citrus peels extract showed the highest nitric oxide scavenging activity of $82.91 \pm 2.4 \%$ at $1000 \mu \mathrm{g} / \mathrm{mL}, 84.61 \pm$ $0.4 \%$ at $200 \mu \mathrm{g} / \mathrm{mL}, 83.90 \pm 0.7 \%$ at $100 \mu \mathrm{g} / \mathrm{mL}$ and $82.91 \pm 1.3 \%$ at $400 \mu \mathrm{g} / \mathrm{mL}$ for orange, mandarin, lime and lemon, respectively. Vitamin $\mathrm{C}$ showed similar nitric oxide scavenging activity to that of citrus fruit peel at 100,200 and $400 \mu \mathrm{g} / \mathrm{mL}$ concentrations ( $p>0.05)$, but significantly higher at 800 and $1000 \mu \mathrm{g} / \mathrm{mL}$ concentrations (Figure 2). Lime peel extract showed the lowest nitric oxide radical scavenging activity $(62.96 \pm 2.15 \%)$ at $1000 \mu \mathrm{g} / \mathrm{mL}$ concentration. Munmar et al. [17] reported the highest nitric oxide scavenging activity of (79.42\%) for Citrus medica peel.

The Nitric Oxide scavenging assay result showed that nitric oxide radical scavenging activity of selected citrus peels did not exhibit similar trends. Nitric Oxide scavenging activity of orange peel extract found increased as the concentration of extracts increases. But, nitric oxide scavenging activity of lime peel extract found decreased as the concentration of extracts increases. Mandarin and lemon peel extracts showed no concentration dependence of nitric oxide scavenging activity. The absorbance of sodium nitroprusside in phosphate buffered saline found decreased when selected citrus fruit peels extract was mixed with it. This showed that the selected citrus fruit peel extract are potential antioxidant. Under aerobic conditions, nitric oxide reacts with oxygen to produce stable products (nitrate and nitrate), the quantities of which can be determined using Griess reagent [27] Antioxidants compete with oxygen to react with nitric oxide generating nitrite [28]. 


\subsubsection{Reducing Power Determination}

Reducing power assay result showed that the reducing power of mandarin and lemon peel was not significantly different $(p<0.05$ ) from concentration of 100 to $1000 \mu \mathrm{g} / \mathrm{mL}$ (Figure 3 ). Vitamin $C$ showed significantly higher reducing power than tested citrus fruit peel at concentration of $200,400,800,1000 \mu \mathrm{g} / \mathrm{mL}(p<0.05)$. Compared to extracts, Lime peel showed significantly the reducing power $(3.8 \pm 0.01)$ at concentrations of $1000 \mu \mathrm{g} / \mathrm{mL}$. A higher reducing power than this study result was reported [29].

The reducing powers of all extracts exhibited concentration-dependant antioxidant activity. The absorption (Reducing power) of selected citrus fruit peel was increased as concentration of the extracts increased. In agreement with this result, Al-anbari and Hassan [18] reported increased reducing power of some citrus leaves and seeds ethanolic extracts. Divya $e t$ al. [19] also reported that reducing power of the Citrus aurantium (bitter orange) fruit peel and pulp increased with increasing concentration for all extracting solvents used. Besides Kim [25] reported the increased reducing powers of Citrus unshiu peel as concentrations was increased from 50 to $3200 \mathrm{ppm}$. In the reducing power assay, the presence of reductants (antioxidants) in the samples would result in the reducing of $\mathrm{Fe}^{3+}$ to $\mathrm{Fe}^{2+}$ by donating an electron forming Perl's Prussian blue. This increases absorbance at $700 \mathrm{~nm}$ [30].

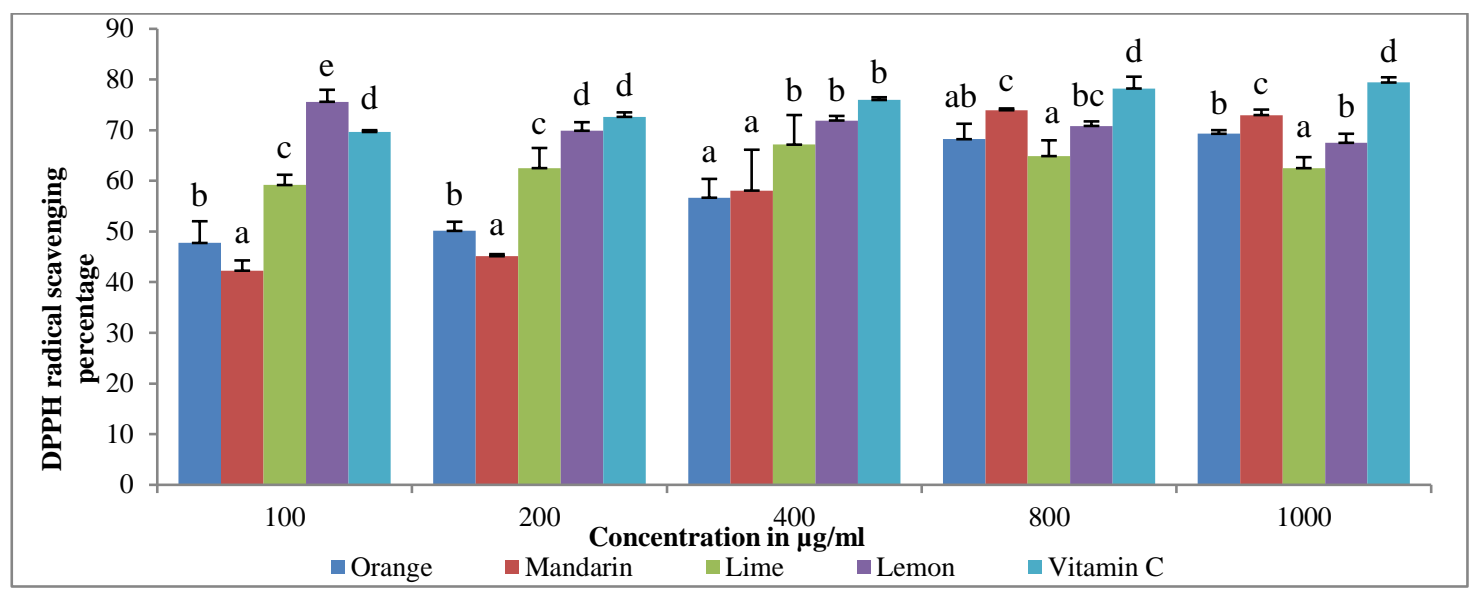

Figure 1. DPPH free-radical scavenging activity of the selected citrus fruit peel's ethanolic extracts. Values are mean with standard deviation. Values not sharing the same letter within concentrations are significantly different from one another $(p<0.05)$.

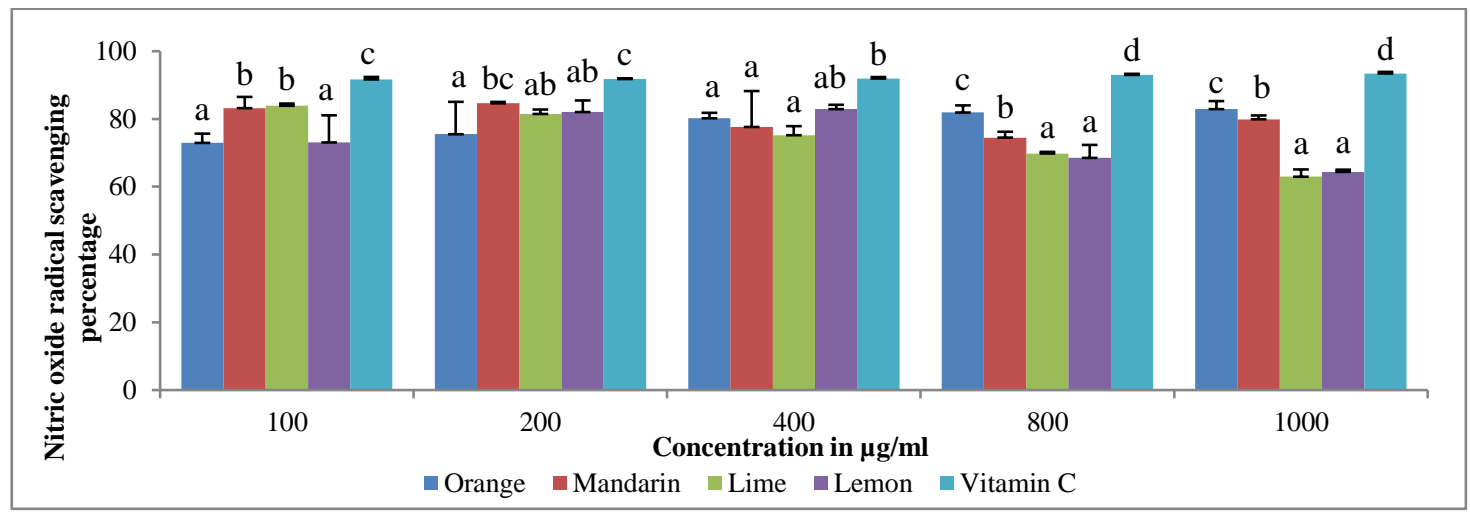

Figure 2. Nitric oxide free-radical scavenging activity of the selected citrus fruit peel's ethanolic extracts. Values are mean with standard deviation. Values not sharing the same letter within concentrations are significantly different from one another $(p<0.05)$. 


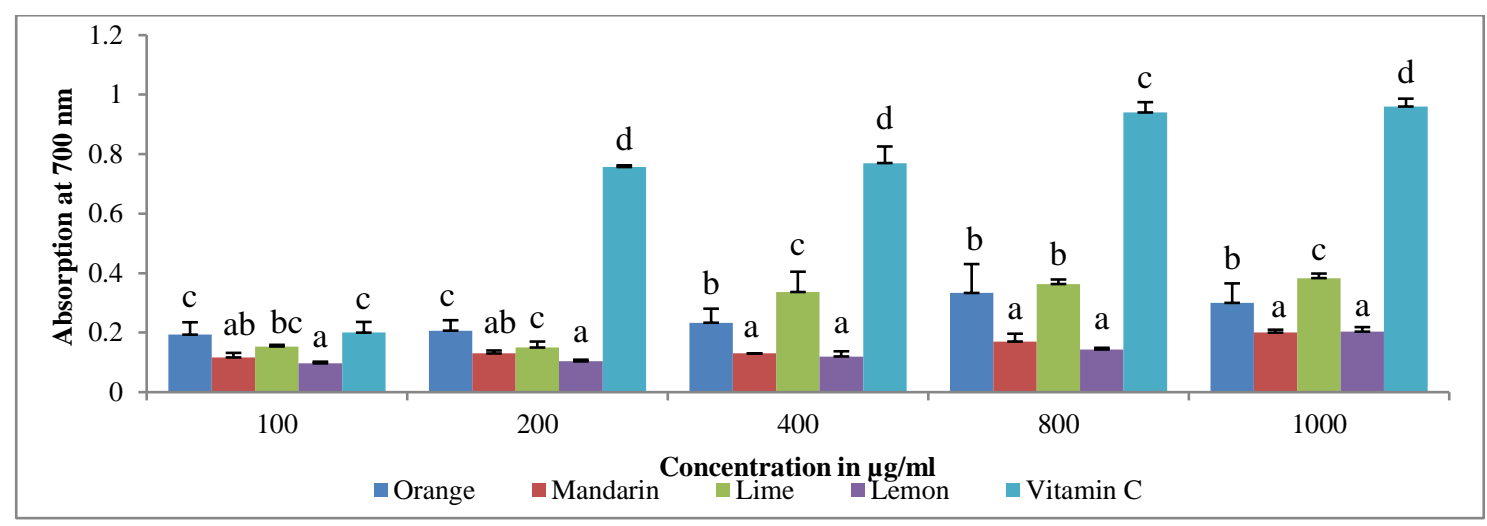

Figure 3. Reducing power of the selected citrus fruit peel's ethanolic extract. Values are mean with standard deviation. Values not sharing the same letter within concentrations are significantly different from one another $(p<0.05)$.

\subsection{Flavonoid Content and Antioxidant Activity}

The correlation between total phenol contents and antioxidant activity of citrus fruit has been widely studied $[7,19,25]$. They reported strong positive association between antioxidant activity of citrus fruits and a concentration of total polyphenol content. Absence of direct dependence between total phenolic content and antioxidant activity of lemon fruit peel was reported [22]. In this present study, an attempt was made to study the association between the in vitro antioxidant activity and flavonoid contents. Linear association between flavonoid contents of selected citrus fruit peel extracts and antioxidant activity was analyzed individually using linear regression analysis and the results were shown in Figure 4, Figure 5 and Figure 6.

Regression analysis revealed strong correlation between flavonoid contents of citrus fruit peel extracts and DPPH assay $\left(\mathrm{R}=0.975, \mathrm{R}^{2}=0.951, p=0.025\right)$ (Figure 4). A weak linear correlations was observed between flavonoid contents and nitric oxide free radical scavenging $(\mathrm{r}=0.734, p=0.266)$ and flavonoid contents and reducing power $(\mathrm{r}=0.612, p=0.388)$. Opposing of this result, lack of correlation between crude methanolic extracts of citrus fruit peel and DPPH radical scavenging activity was reported [7, 8]. The analysis showed insignificant linear correlation between total flavonoids contents of citrus fruit peel extracts and nitric oxide radical scavenging activity $\left(\mathrm{R}=0.734, \mathrm{R}^{2}=0.539, p=0.266\right)$ (Figure 5). A weak and insignificant linear association was also found between flavonoid contents of the citrus fruit peel extracts and reducing power $\left(\mathrm{R}=0.612, \mathrm{R}^{2}=0.374, p=0.388\right)$ (Figure 6). Opposing this result, good correlation between flavonoid content and antioxidant activity in most food samples studied was reported [31].

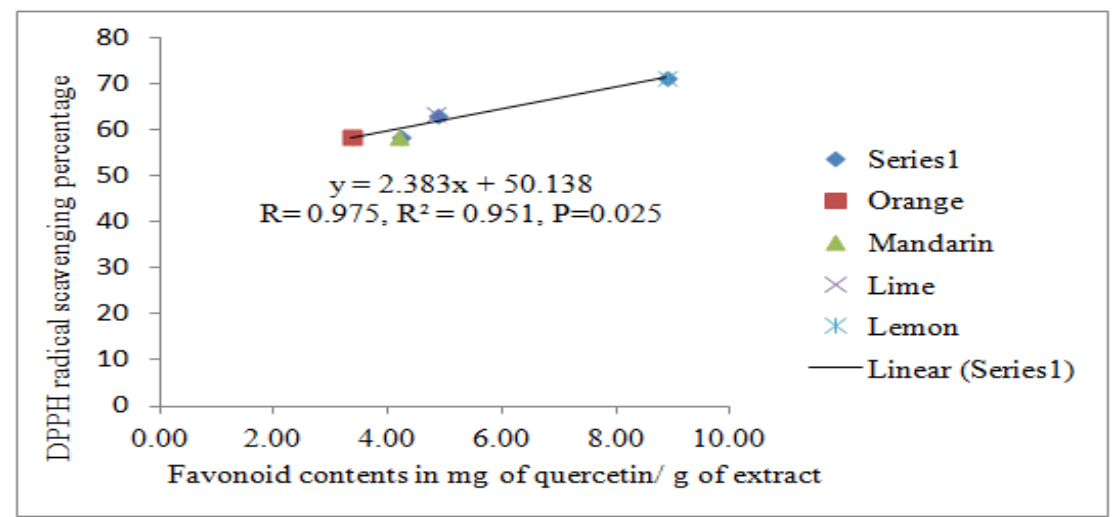

Figure 4. Correlation between flavonoid contents of selected citrus fruit peel and DPPH radical scavenging 
The correlation analysis result indicated that the important factor in determining antioxidant activity potency of flavonoid is its molecular structure rather than content. It has been reported that radical scavenging and metal chelating activities of flavonoids substantially depends upon configuration, substitutions and total number of hydroxyl groups of flavonoids [32]. It was confirmed that the more hydroxyl substitutions in flavonoids structures, the stronger its antioxidant activities [32, 33].

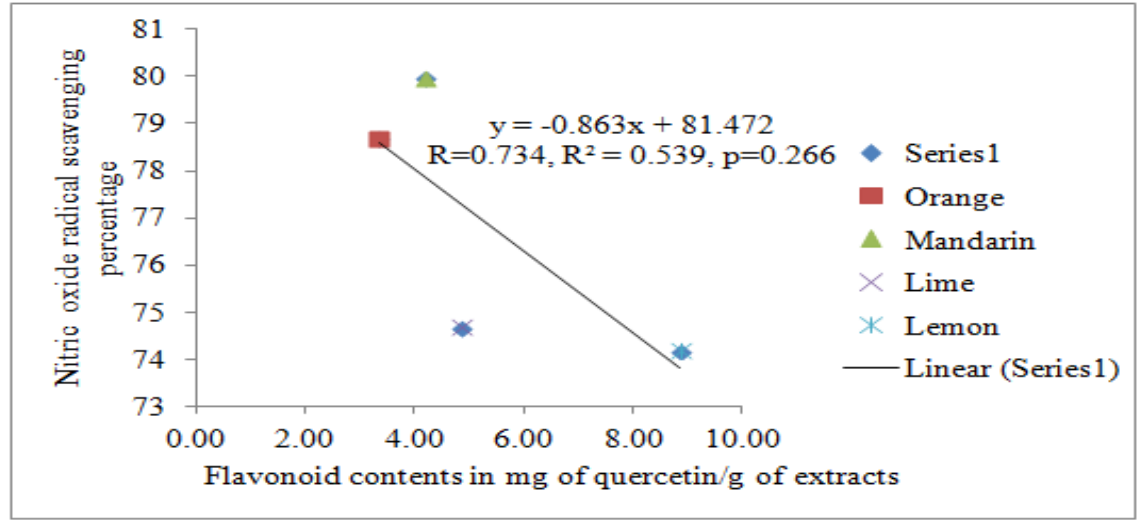

Figure 5. Correlation between flavonoid contents of selected citrus fruit peel and nitric oxide radical scavenging

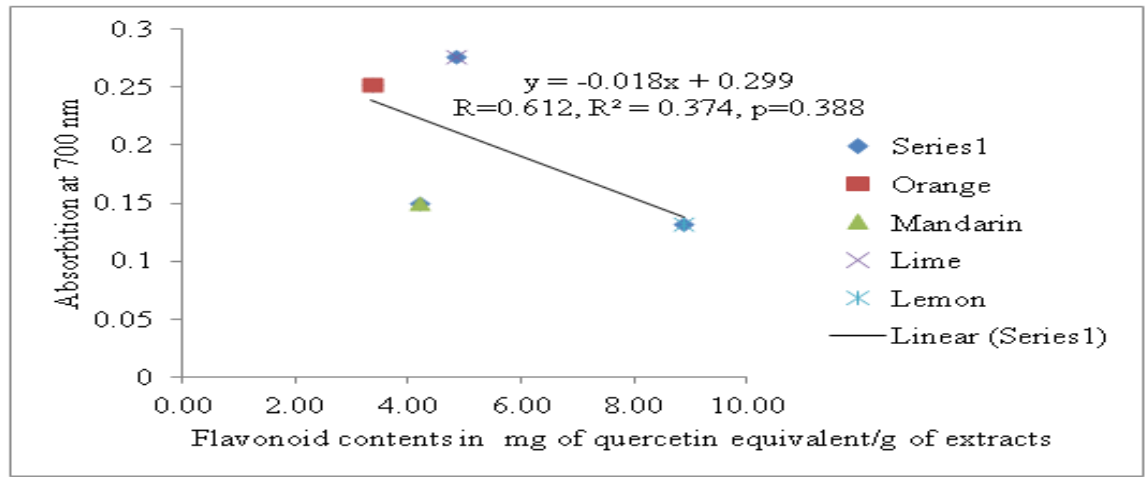

Figure 6. Correction between flavonoid contents of selected citrus fruit peel and reducing power

\section{CONCLUSION}

It can be concluded from the study that the selected citrus peel extracts can act as a potential free radical scavengers and reducing power agent. The important factor in antioxidant activity is molecular structure of flavonoid rather than its contents. Antioxidant assay methods used give different antioxidant activity trends of selected citrus fruit peels.

\section{Acknowledgements}

This paper is part of research megaproject coded HURG-2016-06-01-05. Therefore, the authors are gratitude Haramaya University, office of vice president for research affairs for funding the research. We also express our special thanks to Dire Dawa District, Ethiopia, farmers for allowing us to collect samples of citrus fruit.

\section{Declaration of Conflicting Interests and Ethics}

The authors declare no conflict of interest. This research study complies with research publishing ethics. The scientific and legal responsibility for manuscripts published in IJSM belongs to the author(s). 


\section{Orcid}

Olyad Erba (Dttps://orcid.org/0000-0001-5552-6884

Dereje Atomsa (iD https://orcid.org/0000-0002-6034-6738

Meseret Chimdessa (iD https://orcid.org/0000-0001-5474-1515

Teshome Gonfa (iD) https://orcid.org/0000-0001-5691-6905

\section{REFERENCES}

[1]. Nimse, S. B., Pal, D. (2015). Free radicals, natural antioxidants, and their reaction mechanisms. RSC Adv., 5, 27986-28006. doi:10.1039/c4ra13315c

[2]. Bhattacharya, M., Chakraborty, S. (2015). Free radicals and naturally occurring antioxidants. J Pharmacogn Phytochem., 3, 1-7.

[3]. Lobo, V., Patil, A, Phatak, A., Chandra, N. (2010). Free radicals, antioxidants and functional foods: Impact on human health. Pharmacogn Rev., 4, 118-126. doi:10.4103/0973-7847.70902

[4]. Gorinstein, S., Martín-Belloso, O., Park, Y. S., Haruenkit, R., Lojek, A., Cí̌ž, M., Caspi, A., Libman, I., Trakhtenberg, S. (2001). Comparison of some biochemical characteristics of different citrus fruits. Food Chem., 3, 309-315.

[5]. Yang, X., Kang, S. M., Jeon, B. T., Kim, Y. D., Ha, J. H., Kim, Y. T., Jeon, Y. J. ( 2011). Isolation and identification of an antioxidant flavonoid compound from citrus-processing by-product. J Sci Food Agric., 91, 1925-1933. doi:10.1002/jsfa.4402

[6]. Segev, A., Badani, H., Kapulnik, K., Shomer, I., Oren-Shamir, M., Galili, S. (2010). Determination of polyphenols, flavonoids and antioxidant capacity in colored chick-pea (Cicer arietinum L.). J Food Sci., 75, S115-9. doi:10.1111/j.1750-3841.2009.01477.x

[7]. Ghasemi, K., Ghasemi, Y., Ebrahimzadeh, M. A. (2009). Antioxidant activity, phenol and flavonoid contents of 13 citrus species peels and tissues. Pakistan J Pharm Sci., 22, 277281.

[8]. Asjad, M. M., Akhtar, M. S., Bashir, S., Din, B., Gulzar, F., Khalid, R., Asad, M. (2013). Phenol, Flavonoid Contents and Antioxidant Activity of Six Common Citrus Plants in Pakistan. J Pharm Cosmet Sc., 1, 1-5.

[9]. Bind, A., Singh, A., Prakash, V., Ahmadand, N., Kumar, M. (2015). Evaluation of nonenzymatic and enzymatic antioxidants activity in fruit peels. World J Pharm Pharm Sci., 7, 955-965.

[10]. Lim, S. M., Loh, S. P. (2016). In vitro antioxidant capacities and antidiabetic properties of phenolic extracts from selected citrus peels. Int Food Res J., 23, 211-219.

[11]. Xi, W., Zhang, Y., Sun, Y., Shen, Y., Ye, X., Zhou, Z. (2014). Phenolic composition of Chinese wild mandarin (Citrus reticulata Balnco.) pulps and their antioxidant properties. Ind Crops Prod., 52, p.466-474. https://doi.org/10.1016/j.indcrop.2013.11.016

[12]. El Zawawy, N. A. (2015). Antioxidant, antitumor, antimicrobial studies and quantitative phytochemical estimation of ethanolic extracts of selected fruit peels. Int J Curr Microbiol Appl Sci., 4, 298-309.

[13]. Asmare, D., Derbew, B., Belayneh, A., Mohammed, Y. (2014). Citrus production, constraints and management practices in Ethiopia: the case of pseudocercospora leaf and fruit spot disease. Sci, Techn Arts Res J., 3, 4-18. http://dx.doi.org/10.4314/star.v3i2.2

[14]. Cai, W., Xiaohong, G., Jian, T. (2010). Extraction, purification, and characterisation of the flavonoids from opuntia milpa alta skin. Czech J Food Sci., 28, 108-116. doi:10.17221/122/2009-CJFS

[15]. Sofowora, A. (1996). Research on Medicinal Plant and Traditional Medicine in Africa. $J$ Altern Complement Med., 2, 365-372. http://doi.org/10.1089/acm.1996.2.365

[16]. Ajayi, I. A., Ajibade, O., Oderinde, R. A. (2011). Preliminary phytochemical analysis of some plant seeds. Res J Chem Sci., 3, 58-62. 
[17]. Munwar, S., Roy, H., Rahaman, S. A. (2015). Antioxidant and free radical scavenging activity of Citrus medica. Int J Pharma Res Health Sci., 3, 810-816.

[18]. Al-Anbari, A. K. H., Hasan, M. A. (2015). Antioxidant activity in some citrus leaves and seeds ethanolic extracts. In: International Conference on Advances in Agricultural, Biological and Environmental Sciences, London, UK, 93-97.

[19]. Divya, P. J., Prakash, J., Lakshmi, A. J. (2016). Antioxidant properties of fresh and processed Citrus aurantium fruit. Cogent Food Agric., 2, 1184119. http://dx.doi.org/10.1 080/23311932.2016.1184119

[20]. Yadav, M., Chatterji, S., Gupta, S.K., Watal, G. (2014). Preliminary phytochemical screening of six medicinal plants used in traditional medicine. Int J Pharm Pharm Sci., 6, 539-542.

[21]. Singh, S, Immanuel, G. (2014). Extraction of antioxidants from fruit peels and its utilization in paneer. $J$ Food Process Technol., 5, 349-53. doi:10.4172/21577110.1000349

[22]. Diankov, S., Karsheva, M., Hinkov, I. (2011). Extraction of natural antioxidants from lemon peels. Kinetics and antioxidant capacity. J Univ Chem Technol Metall., 46, 315319.

[23]. Sadaf, Z., Farooq, A., Tahir, M., Bushra, S., Rahman, Q. (2016). Variation in antioxidant attributes and individual phenolics of citrus fruit peels in relation to different species and extraction solvents. J. Chil. Chem. Soc., 2, 2884-2889. http://dx.doi.org/10.4067/S071797072016000200007

[24]. Alam, Md. N., Bristi, N.J., Rafiquzzaman, Md. (2012). Review on in vivo and in vitro methods evaluation of antioxidant activity. Saudi Pharm J., 21, 143-152.

[25]. Arora, M., Kaur, P. (2013). Antimicrobial and Antioxidant Activity of Orange Pulp and Peel. Int J Sci Res., 2, 412-415.

[26]. Kim, J. (2013). Preliminary evaluation for comparative antioxidant activity in the water and ethanol extracts of dried citrus fruit (Citrus unshiu) peel using chemical and biochemical in vitro assays. Food Nutr Sci., 4, 177-188. http://dx.doi.org/10.4236/fns.2013.42025

[27]. Marcocci, I., Marguire, J.J., Droy-lefaiz, M.T., Packer, L. (1994). The nitric oxide scavenging properties of Ginkgo biloba extract. Biochem. Biophys. Res. Commun., 201, 748-755. doi:10.1006/bbrc.1994.1764

[28]. Parul, R., Kundu, S. K., Saha, P. (2013). In vitro nitric oxide scavenging activity of methanol extracts of three Bangladeshi medicinal plants. The Pharma Innovation-J., 1, 83-88.

[29]. Cardenosa, V., Joao, C. M. B., Lillian, B., Arenas-Arenas, F. J., Moreno-Rojas, J. M., Ferreira, I. C. (2015). Variety and harvesting season effects on antioxidant activity and vitamins content of Citrus sinensis Macfad. Mol., 20, 8287-8302. doi:10.3390/molecules20058287.

[30]. Mahmoudi, M., Ebrahimzadeh, M. A., Ansaroudi, F., Nabavi, S. F., Nabavi, S. M. (2009). Antidepressant and antioxidant activities of Artemisia absinthium L. at flowering stage. Afr J Biotechnol., 8, 7170-7175. doi:10.5897/AJB09.753

[31]. Calado, J. C. P., Albertão, P. A., de Oliveira, E. A., Letra, M. H. S., Sawaya, A. C., Marcucci, M. C. (2015). Flavonoid contents and antioxidant activity in fruit, vegetables and other types of food. Agric Sci., 6, 426-435. http://dx.doi.org/10.4236/as.2015.64042

[32]. Heim, K. E., Tagliaferro, A. R., Bobilya, D. J. (2002). Flavonoid Antioxidants: Chemistry, metabolism and structure-activity relationship. $J$ Nutr Biochem., 13, 572-584. https://doi.org/10.1016/S0955-2863 (02)00208-5 
[33]. Cao, G., Sofic, E., Prior, R. L. (1997). Antioxidant and pro-oxidant behavior of flavonoids: structure activity relationships. Free Radic Biol Med., 22, 749-760. doi:10.1016/s08915849(96)00351-6 